\title{
HIGH-PRESSURE MECHANICAL PROPERTIES OF MERLIN ALLUVIUM
}

\author{
B. P. Bonner \\ A. E. Abey \\ H. C. Heard \\ R. N. Schock
}

Suly 7, 1972

Prepared for U.S. Atomic Energy Commission under contract No. W-7405-Eng-48

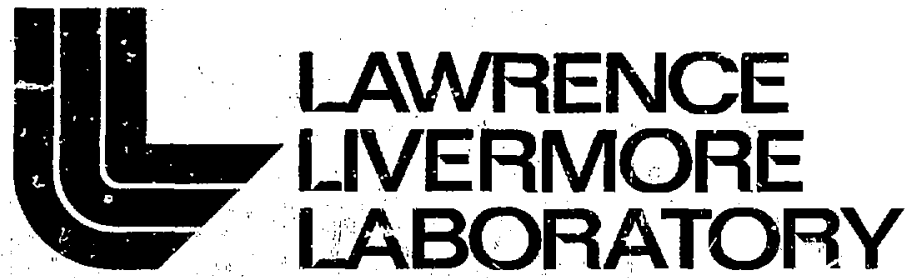

University of California/Livermore 
TID-4500, UC -34

Physics

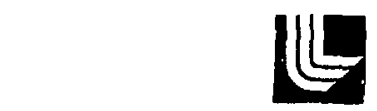

\section{LAWRENCE LNERMORE LAEORATORY}

unversily of Calfomia, Livemore, Calfornia 94550

LCRL -51252

\section{HIGH-PRESSURE MECHANICAL PROPERTIES OF MERLIN ALLUVIUM}

B. P. Bonner, A. E. Abey, H. C. Heard, ind R. N. Schock

MS. date: July 7,1972

NOTICE

Thls repoct was prepared as an account of work sponsorad by the United States Government. Netther the United States nor the United States Atomic Energy Commission, nor any of their employees, nor any of their contractors, subcontractors, or thelr employees, makes any warranty, express or implied, or assunnes any legal linbility or respinsibility for the accuracy, com. pletenest or usefulness of any information, apparatus, product or process disclised, or ropresents that its use would not infringe privately owned rights. 


\title{
HIGH-PRESSURE MECHANICAL PROPERTIES OF MERLIN ALLUVIUM
}

\begin{abstract}
Mechanical properties measurements for desert alluvium from borehole Ue3-ct, Nevada Test Site, have been made as a function of pressure up to 30 koar.

Pressure-volume relations, compressive shear strength, shear response during uniaxial strain, and ultrasonic compressional velocity are reported. Data include results for large $(10-15 \mathrm{~cm}$ diam by about $20 \mathrm{~cm}$ ) samples prepared from intact recovered cores. Compressions of $\sim 30 \%$ occur under quasihydrostatic pressures

of $30 \mathrm{kbar}$, with $65^{0 ;}$ of this deformation taking place in the first 2 kbar. Shear strengths $(\tau)$ vary with water content for samples fabricated from the same aliuvium; $\tau=600$ bars for the air dry material and 2 bars when the material is water saturated (mean pressure $\cong 2$ kbar). The uniaxial strain loading path (strain rate $\cong 10^{-5} / \mathrm{sec}$ ) appruaches the failure envelope in deviatoric stress/mean stress space at $7 \cong 100$ bars and $\mathrm{P}_{\mathrm{m}}$ $\cong 365$ bars.
\end{abstract}

\section{Introduction}

The mecharical properties of alluvium from the Merlin site were measured as part of the effort to calculate seismic coupling efficiencies in porous low $-Q$ earth media. Equation of state data include the pressure-volume relation to 30 kbar, the shear strength/mean pressure envelope to $3 \mathrm{kbar}$, three dimensional stressstrain measurements during uniaxial strain loading, and ultrasonic compressional velocity to 2 kbar confining pressure.

Merlin alluvium is a weakly cohesive, poorly sorted clastic, composed largely of quartz, feldspars, clay minerals, and igneous rock and tuff fragments. Some carbonate, either as calcite caliche or dolomite particles, may be present.
Ramspott et al. ${ }^{1}$ summarise much of the available mineralogical and chemical data fo: Yucca Flat alluvium, but data for the Merlin site itself are not available.

New apparatus and techniques were developed to make most of the deformation measurements. Both large (10$15 \mathrm{~cm}$ diam by $24 \mathrm{~cm}$ ) and small $(\sim 2 \mathrm{~cm}$ diam by $4 \mathrm{~cm}$ ) cylindrical samples were tested. Large sample results were necessary since the alluvial material included particles up to $3 \mathrm{~cm}$ across, and the effects of such heterogeneities had to be asseiser. Brth disaggregated material and undisturbed cores were tested in order to give results representative of in situ mechanical properties. 


\section{Experimental}

Intact cores were recovered from borehole Ue3-ct, A rea 3, Nevada Test Site (NTS), from four depths: $119 \mathrm{~m}$ (392 ft), $175 \mathrm{~m}(575 \mathrm{ft}), 212 \mathrm{~m}(698-700 \mathrm{ft})$, and $309 \mathrm{~m}$ (1016 ft).

Care was taken to minimize disturbances during sample preparation, and the in situ water contents were maintained as nearly constant as possible. Additional deformation experiments were perfo:med on reconstituted alluvium, prepared in the laboratory. In some cases, previously tested samples were disaggregated, and tuen hand packed to the resired density after the appropriate water content had been added. In other instances, samples were fabricated from materials which lost all cohesion when removed from the coring tube. Although the pracedure somewhat alters the microscopic structure of the test sample, few undirturbed samples were available, and supplemental data were required. One percent gypsum $\left(\mathrm{CaSO}_{4} \cdot 2 \mathrm{H}_{2} \mathrm{O}\right)$ was used in a few samples as a cementing material. All reconstituted samples were fabricated from the Ue3-ct material, unless stherwise noted. All Jarge samples were seassoned to 20 bars confining pressure before testing (approximate overburden pressure at $100 \mathrm{~m}$ ) to ensure close cortact between the jacket and sample before placement of the foil strain gages.

Large sample deformations were performed in a $h_{j}$ drostatic piston-cylinder device, specifically designed and constructed to test these cores. Hydrostatic pressures to 2 kbar and separately controlled end loads can be applied in the apparatus. Principal strains are meas- ured with foil strain-gages. Axial strain can also be deduced from piston displacement. Detailed descriptions of the apparatus and samples are given in the Appendix.

The apparatus and techniques used in small sample deformation experiments have been described elsewhere. ${ }^{2-4}$ Briefly, the pressure-volume relation to $30 \mathrm{kbar}$ was determined in a pistoncylinder device in which piston displacement was measured accurately as the load was increased. The pressure trarsmitting medium is tin and, since the shear strength of this material is low but finite, the stress distribution is quasihydrostatic. Shear strengths were determined from axial stress-strain measurements made on jacketed samples at different confining pressures. Precise three dimensional stress-strain measurements were made on metal jaciketed specimens ising foil strain gages, as the material was loaded in uniaxial strain. These stress and strain measurements determine deformation moduli along a low strain-rate path that simulates plane shock loading. In all instances, the axial load was corrected for the strength of the jacketing materials.

Water contents were determined after teste by drying to constant weight at $110^{\circ} \mathrm{C}$. Large sample volumes were determined to $\sim 1 \%$ using a fluid displacoment technique for density calculations.

\section{PRESSURE-VOLUME MEASUREMENTS}

The pressure--volume relationships for alluvium from the test site were determined in two pressure ranges: from 
1 bar to 30 kbar in a quasihydrostatic system and irom 1 bar to $2 \mathrm{kbar}$ in a hydrostatic system. The quasihydrostatic apparatus takes samples $2.03 \mathrm{~cm}$ diam by $2.54 \mathrm{~cm}$. Saniples $10.1,12.7$, or $15.2 \mathrm{~cm}$ diam by $17.8 \mathrm{~cm}$ were used in the hydrostatic system. Tin is the pressure medium in the quasihydrostatic system and the lead jacketing separates the sanple from the oil pressure medium in the rycrostatic system.

Two types of alluvium were used in constructing the pressure-volume samples. Both of the samples used in the quasihydrostatic system and all but five of the hydrostatic samples were fabricated from reconstituted alluvium. Five undisturbed samples, from Ue3-ct cores, survived the trip from in situ to apparatus. Three of these samples were from the $309 \mathrm{~m}$ level while the other two were irom $119 \mathrm{~m}$.

The 30 kbar data are presented in Fig. 1. Both samples had initial densities of $1.65 \mathrm{gm} / \mathrm{cc}$ with $10 \%$ water content by weight. The data from the two samples appear to be in very good agreement.

Figures 2 and 3 present the data from the large sample 2 kbar hydrostatic system along with the 1 to 2 kbar data from the quasihydrostatic system. Table 1 lists the different samples and gives the symbols used to show data points in

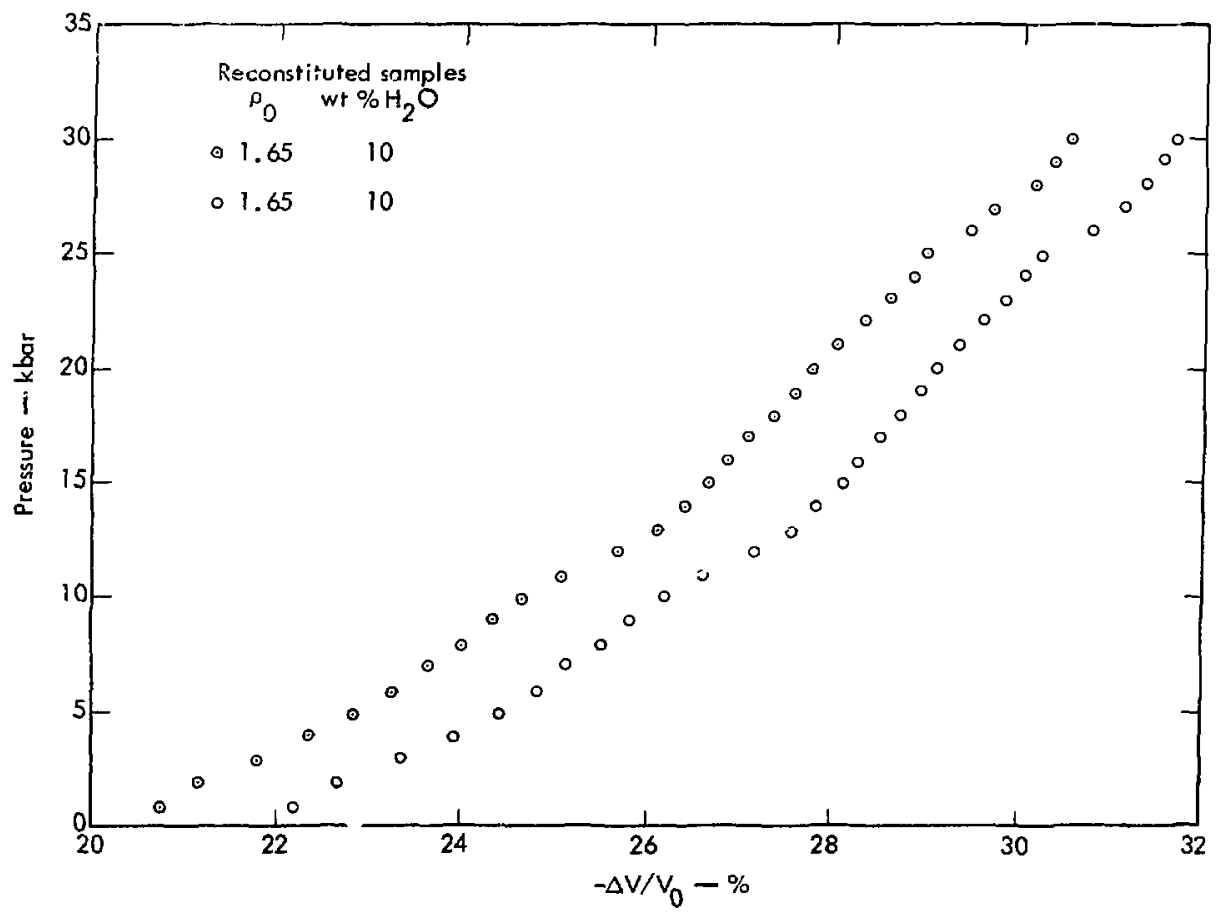

Fig. 1. Pressure-volıme relations to $30 \mathrm{kbar}$ for reconstituted alluvium. 


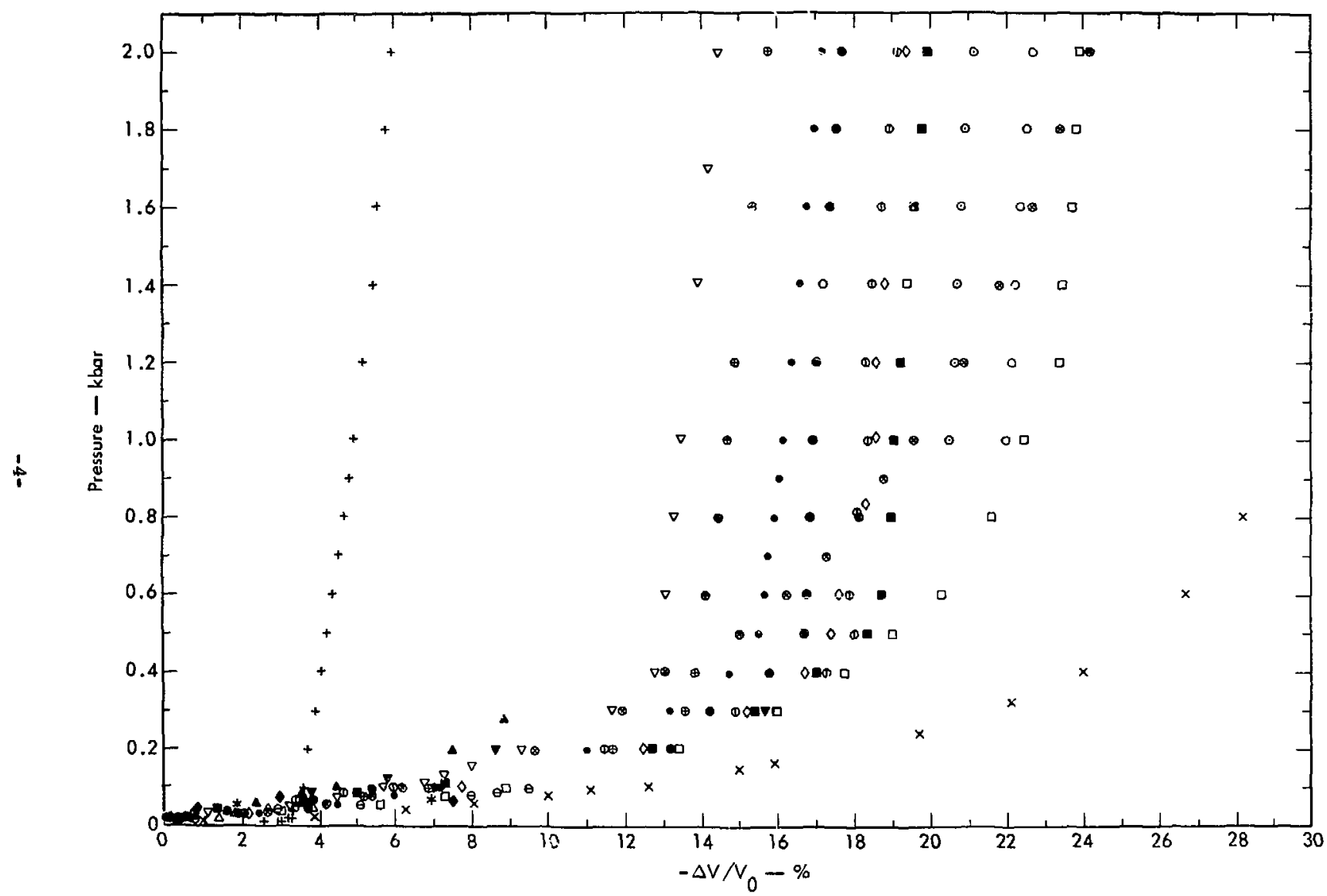

Fig. 2, Summary of pressure-volume data. 


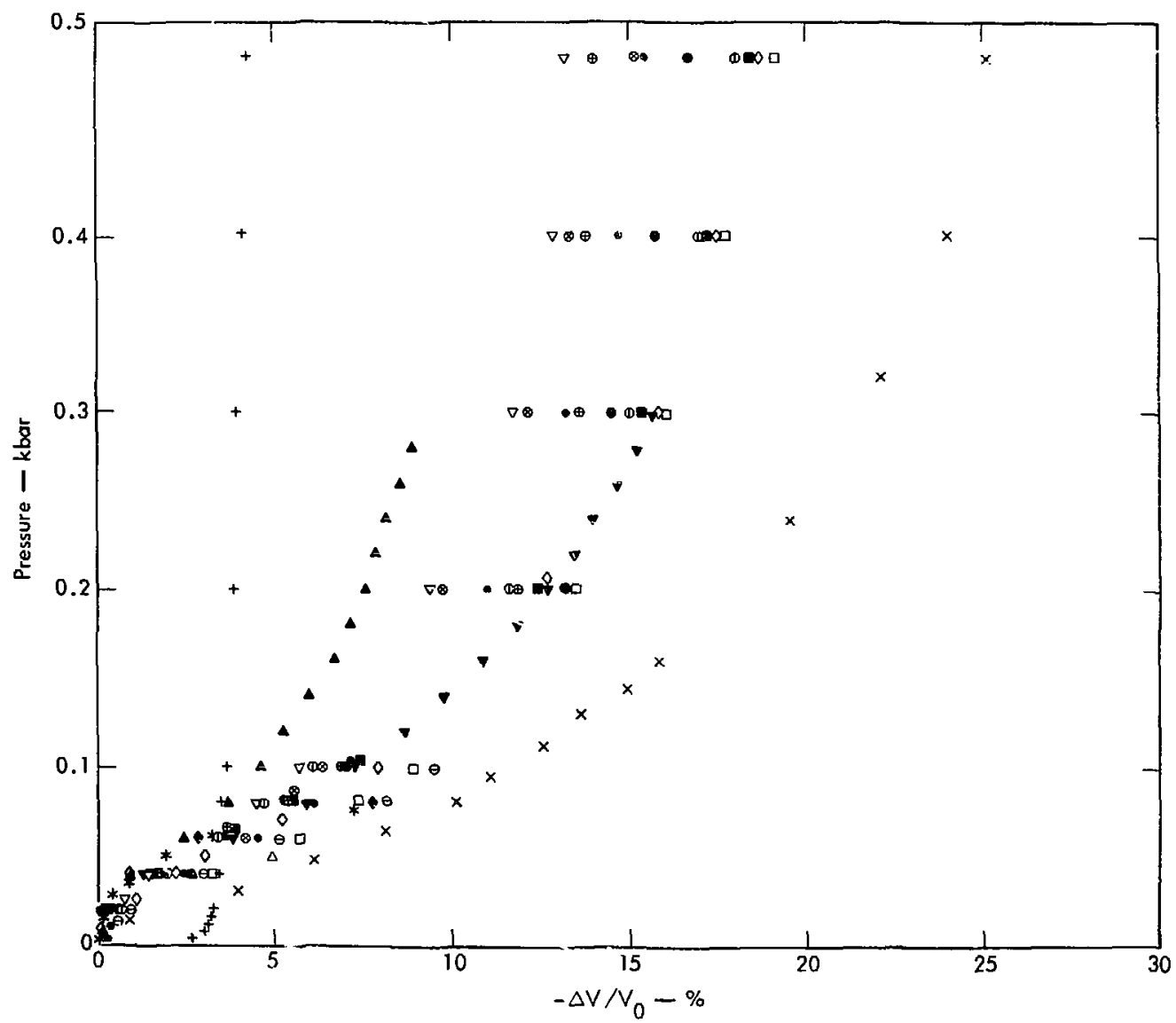

Fig. 3. Pressure-volume relations to $\mathbf{5 0 0}$ bars. 
Table 1. Density, water content and depth, Merlin allusium Ue3-ct. Rrconstituted samples not representative of any depth. Symbol key identifies data points in Figs. 2 and 3.

\begin{tabular}{|c|c|c|c|c|}
\hline & & $\rho_{0}$ & $\mathrm{Wt} \% \mathrm{H}_{2} \mathrm{O}$ & Lepth-m \\
\hline \multirow{5}{*}{ 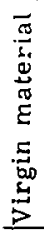 } & $\theta$ & 1.57 & - & 309 \\
\hline & - & 1.57 & 17.2 & 309 \\
\hline & 0 & 1.57 & 17 & 309 \\
\hline & $\bullet$ & 1.56 & 12 & 119 \\
\hline & * & 1.57 & - & 119 \\
\hline \multirow{14}{*}{ 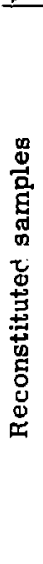 } & $\bullet$ & 1.82 & 10 & \\
\hline & $x$ & 1.60 & 8 & \\
\hline & $\oplus$ & 1.95 & 14.5 & \\
\hline & $\Delta$ & 1.61 & 11 & \\
\hline & $\nabla$ & 1.68 & 8 & \\
\hline & 口 & 1.74 & 10 & \\
\hline & $\otimes$ & 1.50 & 0 & \\
\hline & + & 2.02 & 20 & \\
\hline & $\boldsymbol{\nabla}$ & 1.57 & 7 & \\
\hline & $\Delta$ & 1.57 & 7 & \\
\hline & - & 1.64 & 10 & \\
\hline & च & 1.71 & 10 & \\
\hline & 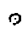 & 1.65 & 10 & \\
\hline & 0 & 1.65 & 10 & \\
\hline
\end{tabular}

Figs, 2 and 3 . The 2 kbar data include a strain gage correction as discussed in the Appendix. While there is scatter in these results, a general picture of the pressurevolume relation is evident. The position of the lowest break in the curve (at about 40 bars, Fig. 3) is related in the frictional stress between the individual grains. Below this break the frictional stress $E$ :eatly impedes any movement of grains. Above this break, the external stress overcomes the friction between grains and relatively iarge movements can take place. In the saturated sample (signified by + in
Figs. 2 and 3 ), the high water pressure reduces the normal stress between grains and the frictional forces between grains are less important. Above about $6 \mathrm{C}$ bars, the alluvium is quite compressible up to a knee region: at somewhat higher pressures the curves become quite steep. The position of the knee appears to be a function of the initial properties of the sample, such as water content and density. Unfortunately, there is too much scatter to dete:min 2 a functional relationship for the position of the knee.

Three large reconst:tuted samples were fabricated from one batch of previously tested Ue3-ct alluvium in an attempt to determine the effect of water on the pressure-volume curves. Water contents were 0,10 , and $20 \%$ by weight. These are signified by $\otimes, \cdot$, and + respectively in Figs. 2 and 3 . These three curves give a graphic example of how water not only affects the position but the shape of the curve, i.e., the higher the water content the sharper the knee and the smaller the volume change at which the knee occurs.

The five curves lor intact cores in Fig. 2 signified by $\theta,+, \diamond, \oplus$ are in quite good agreement considering the heterogeneity of the starting material. There are not enough data to determine the effect (if any) of depth on the pressurevolume curves, however.

The bulk modulus calculated from the quasi-hydrostatic curves in Fig. $2(0,0)$ is in excellent agreement with bulk modulus predicted from the results on the large sample tests in the pressure region from 1 to $2 \mathrm{kbar}$. The low pressure ( 1 to 500 bars) data given in Fig. 2 are replotted on a larger scale in Fig. 3 
as an aid in following the individual loading paths.

Figure 4 shows our best estimate of a pressure-volume relationship for alluvium containing $10 \%$ water. The insert magnifies the lower pressure region to show both a loading and unloading curve. Fror loading, the initial bulk modulus is $4 \mathrm{kbar}$, decreasing to about $1 \mathrm{kbar}$ in the pressure region from 40 to 100 bars. In the 1 kbar to 2 kbar portion of the curve, the bulk modulus increases to $120 \mathrm{kbar}$. In general, there were no systematic differences between the data for alluvium recovered intact from the coring tube and for the reconstituted material if similar density and water content.
The same "best estimate" data is replotted in Fig. 5 in pressure/specific volume space with data for quartz $\left(\rho_{0}\right.$ $=2.65$ ).

At the highest stresses attained in our experiments ( $30 \mathrm{kbar})$ the alluvium is relatively compressible. We believe that for stresses greater thar several hundred kbar, the quartz data may represent an upper limit for deformation of the alluvium.

\section{UNIAXIAL COMPRESSION TESTS}

Three types of alluvial material were used here in determining the shear strength properties in compression. These were: 1) the preserved coherent

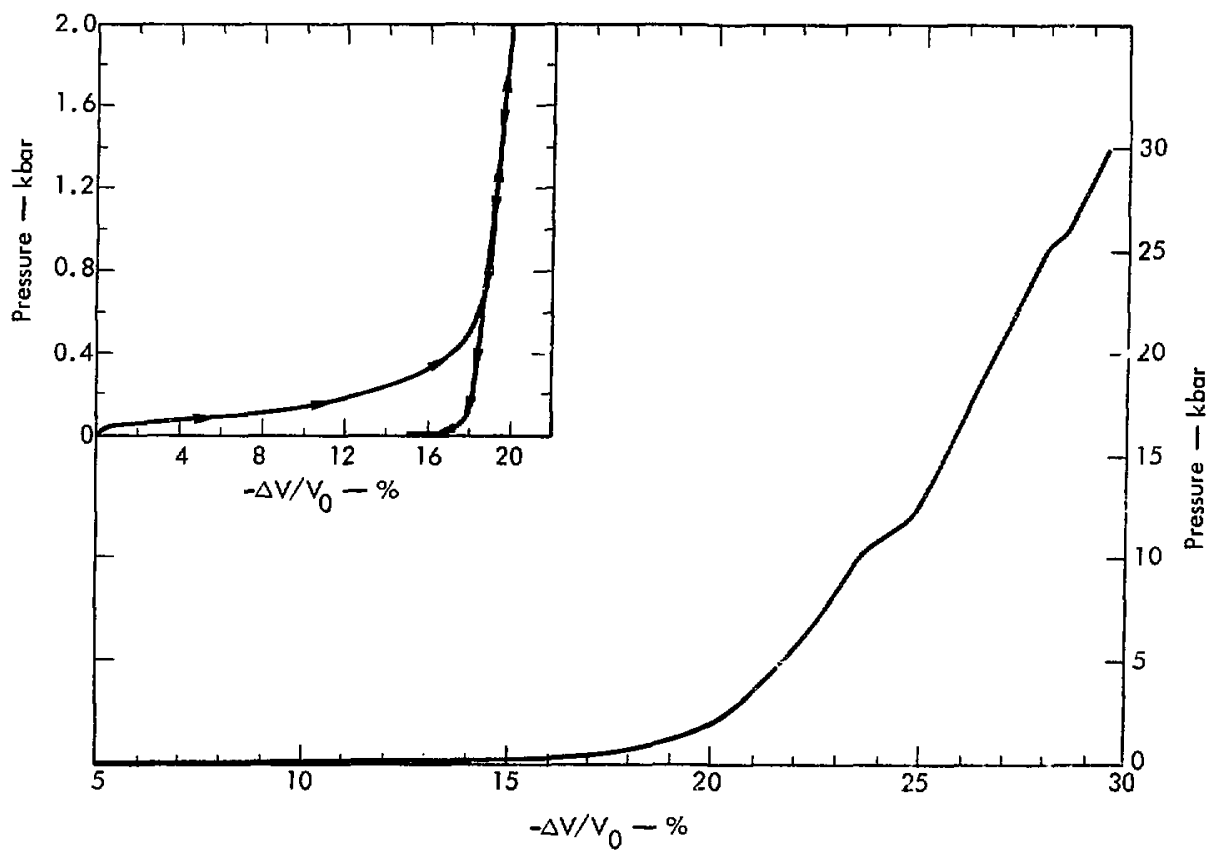

Fig. 4. "Best fit" pressure-volume relation for alluvium containing $10 \%$ water. 


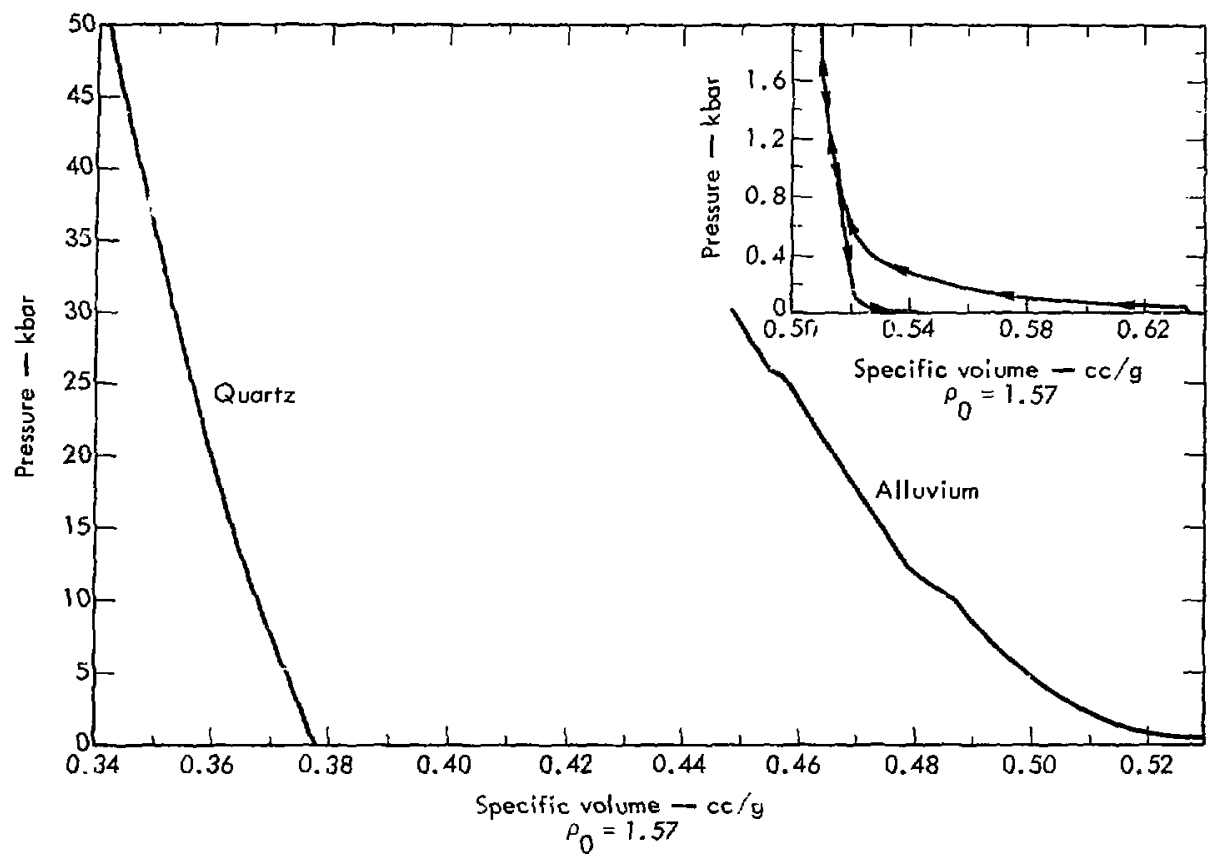

Fig. 5. "Best fit" replotted in pressure/specific volume $s_{k} \cdot c e$, with data for quartz.

core samples from hole Ue3-ct taken at depths of 119, 175, 212, and $309 \mathrm{~m}$; 2) disaggregated alluvial material from these core samples; and 3) disaggregated alluvium ("Nevada fines") which was lightly recemented with $1 \% \mathrm{CaSO}_{4} \cdot 2 \mathrm{H}_{2} \mathrm{O}$. All three materials were formed into cylindrical samples either $10 \mathrm{~cm}$ or $15 \mathrm{~cm}$ in diameter by either 17.5 or $20 \mathrm{~cm}$ in length and jacketed in $0.16 \mathrm{~cm}$ lead tubing. In all cases, the resulting differential stress/axial strain curves have been correcter for the force borne by this jacketing. The strain rate for all tests reported here remained nearly constant at about $10^{-5} /$ second.

In most of the experiments with coherent cores, the water content was meas- ured after the test; in a few cases, jacket leakage precluded these determinations. Most of the remaining cohesionless and recemented samples tested had 7-8\% (by weight) water. Several samples of the cohesionless alluvium were run with water contents ranging from $0 \%$ (dry) to $20 \%$ (fully saturated). All of the strength data as well as other pertinent information are summarized in Table 2 ,

The confining pressures for the uniaxial compression tests discussed here ranged from 80 to 2000 bars. Regardless of the starting material, measured stressstrain curves were similar in general shape provided the materials were of similar water content. The relative amount of water, however, strongly 
Table 2. Merlin alluvium Ue3-ct. All principal stresses measured at $5 \%$ longitudinal strain,

\begin{tabular}{lccrrrrrr}
\hline $\begin{array}{c}\text { Depth } \\
\mathrm{m}\end{array}$ & $\begin{array}{c}\text { Initial } \\
\rho_{0} \\
(\mathrm{~g} / \mathrm{cc})\end{array}$ & $\begin{array}{c}\mathrm{H}_{2} \mathrm{O} \\
\text { content } \\
\%\end{array}$ & $\begin{array}{c}\sigma_{1} \\
\text { (bars) }\end{array}$ & $\begin{array}{c}\sigma_{2} \\
\text { (bars) }\end{array}$ & $\begin{array}{c}\sigma_{3} \\
\text { (bars) }\end{array}$ & $\begin{array}{c}{ }^{2} \\
\text { (bars) }\end{array}$ & $\begin{array}{c}\mathrm{P}_{\mathrm{m}} \\
\text { (bars) }\end{array}$ & Remarks $^{2}$ \\
\hline 119 & 1.56 & 12.0 & 92 & 80 & 80 & 6 & 84 & $\mathrm{~A}$ \\
305 & 1.57 & - & 192 & 100 & 100 & $4 \mathrm{C}$ & 131 & $\mathrm{~B}$ \\
175 & 1.57 & 7.0 & 570 & 300 & 300 & 135 & 390 & $\mathrm{C}$ \\
- & - & 8.0 & 375 & 300 & 300 & 38 & 325 & $\mathrm{D}$ \\
- & - & 8.0 & 1300 & 1000 & 1000 & 150 & 1100 & $\mathrm{D}$ \\
212 & - & - & 2110 & 1800 & 1800 & 155 & 1903 & $\mathrm{~A}$ \\
309 & 1.60 & 8.0 & 2340 & 2000 & 2000 & 170 & 2113 & $\mathrm{~B}, \mathrm{C}$ \\
309 & 1.57 & 17.2 & 2145 & 2000 & 2000 & 73 & 2048 & $\mathrm{~B}$ \\
- & 1.50 & 0 & 3220 & 2000 & 2000 & 610 & 2407 & $\mathrm{C}$ \\
- & 1.68 & 8.0 & 2108 & 2000 & 2000 & 54 & 2036 & $\mathrm{C}$ \\
- & 1.82 & 10.0 & 2315 & 2000 & 2000 & 157 & 2105 & $\mathrm{C}$ \\
- & 1.95 & 14.5 & 2110 & 2000 & 2000 & 55 & 2037 & $\mathrm{C}$ \\
- & 2.02 & 20.0 & 2003 & 2000 & 2000 & 2 & 2001 & $\mathrm{C}$ \\
\hline
\end{tabular}

${ }^{a}$ Remarks code
A. $10 \mathrm{~cm} \mathrm{diam}$
B $15 \mathrm{~cm}$ diam
C Cohesionless sample
$D$ Cohesionless sample recemented with $1 \% \mathrm{CaSO}_{4} \cdot 2 \mathrm{H}_{2} \mathrm{O}$ 
influences the stress level of each curve, with the dry alluvium being of highest strength and having very strong work hardening (strongly positive slope of the stress-strain curve, after the elastic limit). Intermediate water content material typically gave lower strengths and gave little work hardening after the yield point followed by a region of more or less constant stress level or occasionally by slight work softening (negative slope of the stress-strain curve). At high water contents, strengths were usually low and work hardening nearly absent.
The differential stress characteristic of this suite of materials was not a monotonically increasing (or decreasing) function of strain. We decided, in order to correlate the results, to compare either the stress value at $5 \%$ longitudinal strain or the peak (ultimate) stress in those cases where the curve reached a maximum at strains less than 5\%. All test results are thus shown in Fig. 6 plotted in shear stress/mean pressure space. In addition, similar results ${ }^{5}$ measured on small cylinders of disaggregated alluvium from Ue3-ct at 7-8\% water content are also included for comparison.

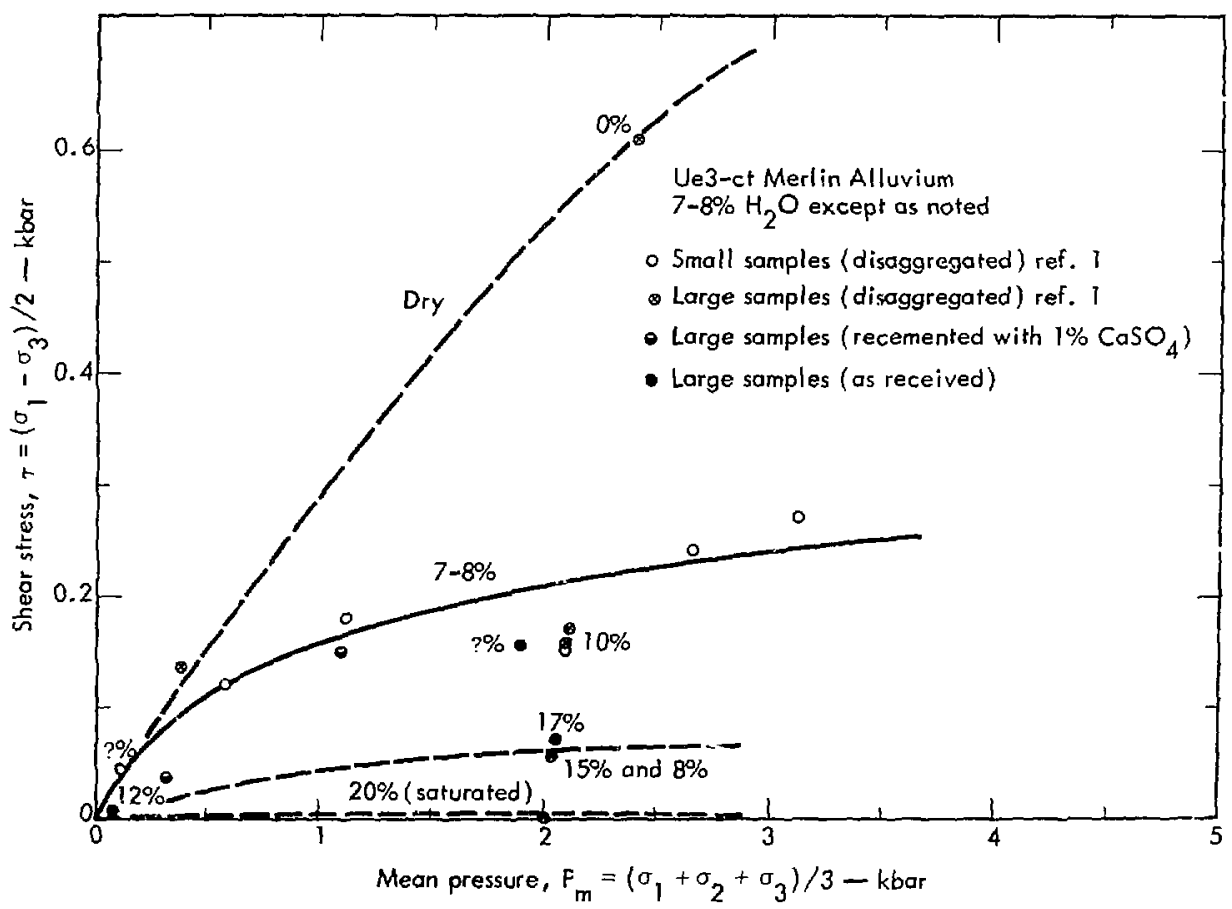

Fig. 6. Failure envelopes for alluvium with varying water content plotted in shear stress mean pressure space. 
Considering first all data measured on the alluvial materials at $7-8 \%$ water content, sevezal trends immediately became obvious (Fig. 6). All results for this intermer!ate water content, with a single exception near $(55,2040)$ bars, seem to cluster along a rather narrow band about the solid-curve failure envelope as shown. This envelope has a slope of about 0.25 up to mean pressures of about $0.5 \mathrm{kbar}$; in the region 0.5-3 kbar the slope markedly decreases to about 0.05 . It may also be noted that differences in the sizes of the test samples (by a factor of 4-5.3 in linear dimensions; 115-340 in volume) apparently do not affect the failure behavior within this data scatter band. Further, both the disaggregated and lightly-cernented material give similar results. The alluvium at the $7-8 \%$ water content thus seems qualitatively similar to several other weak hetrogeneous silicate materials (e.g., tuff with about $8 \%$ water content ${ }^{6,7}$ ).

There is also the definite suggestion in Fig. 6 that the shear strength is directly influenced by the initial water content. In Fig. 7, we have compared all shear strengths with the measured water contents for these materials tested at 2 kbar confining pressure $(2.0-2.4 \mathrm{kbar}$ mean pressure). It is clear that, under these conditions, the strength is approximately linearly relates to water content in the $40 \%-100 \%$ saturation range (8-20 wt \% water) but at lower water contents the strength seems to be much more sensitive. If this behavior is assumed to occur at both higher and lower levels of mean pressure, then the strengths of any similar NTS alluvium at mean pressures up to about 3 kbar may be qualitatively

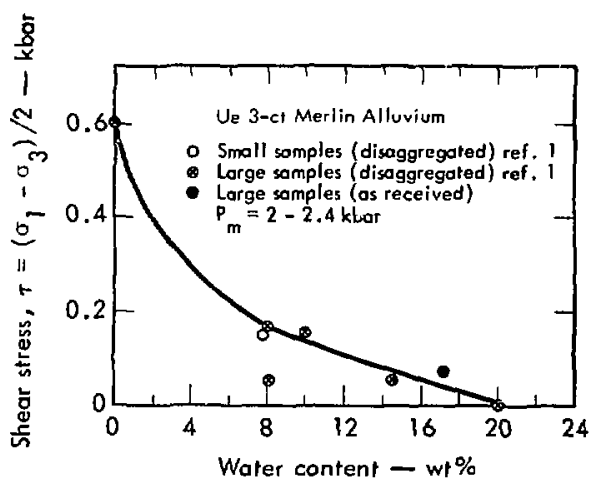

Fig. 7. Shear strength as a function of water content ( $w t \%$ ) for alluvium.

predicted from the known water content, given the results shown in Figs, 6 and 7 . Quantitative prediction must await more data measured for other alluvia over a wider range of pressure and water contents.

\section{UNIAXIAL STR AIN MEASUREMENTS}

Deformation under conditions of uniaxial strain was carried out an two large alluvium specimens from the Merlin site. Sample dimensions were approximately $10 \mathrm{~cm}$ in diameter and $25 \mathrm{~cm}$ in length. These samples were jacketed in $0.16 \mathrm{~cm}$ thick lead to prevent the confining pressure fluid from penetrating the pore space. Only one sample remained intact through the sample preparation piocedure, the other partially crumbled and some of the loose material had to be poured into th. sample jacket.

In the uniaxial strain experiment, axial stress $\left(\sigma_{1}\right)$ is increased while radial strain ( $\epsilon_{r}$ ) remains constant. This condition is accomplished by increasing the 
confining pressure, or radial stress $\left(\sigma_{3}\right)$, at a rate appropriate to maintain a fixed sample diameter while the samle is being axially loaded. These are the conditions thought to exist during loading by a plane shock-wave where the strain rates are such $\left(10^{2}-10^{6} \mathrm{sec}^{-1}\right)$ that inertial requirements preclude strain excent in the direction of the propagating front. The strain rate of these experiments, however, is much lower $\left(\sim 10^{-5} \mathrm{sec}^{-1}\right)$ and one may a priori expect strain rate effects (lateral grain motion) which give rise to a departure in stress state from actual shockloading conditions, especially at high differential stresses. If all inelasticity under shock-loading were due to strainrate dependent phenomena, extrapolating initial loading slopes might yield the actual shock-loading slopes. In reality, these slopes give an upper limit to the actual shock loading path while the low strain rate laborator $y$ data place a lower limit on this path.

The aggregated sample $\left(119 \mathrm{~m}, \rho_{0}\right.$ $=1.56 \mathrm{~g} / \mathrm{cm}^{-3}, 12 \%$ water content $)$ was first loaded hydrostatically $\left(\sigma_{1}=\sigma_{3}\right)$ to 80 bars and the uniaxial strain experiment carried out from this point. This allows for initial loading beyond the seasoning pressure (20 bars) and ensures that the jacket is firmly bonded to the material. The pressure is not significantly higher than overburden pressure, however, and loading should be representative of loading of the actual material at depth. Figure 8 presents the observed loading curve in stress difference/radial stress space for this aggregated sample. It is observed that the loading slope shows curvature from initial loading and that the slope decreases as end load increases. Further- more the loading continues to a point at or very near the yield curves previously. discussed, indicating that the material being loaded in uniaxial strain is yielding in a similar fashion.

Strain response is shown in Fig. 9. It is observed that the axial stress and mean pressure increase linearly at first, followed by a break and softening of the loading curve, in turn followed by a pronounced stiffening at comparable mean pressures and in a similar manner to that observed in purely hydrostatic loading. In addition the difference between the two curves $(4 / 3 \tau)$ increases with increasing load in agreement with a failure surface previously shown to be an increasing function of mean pressure. In a typical elastic brittle solid the shear stress $(\tau)$ in uniaxial strain loading is observed to increase until the material fails; beyond that the shear stress level increases only slightly as the failure envelope increases.

The initial break in the loading curve in Fig. 9 may represent the breakdown of

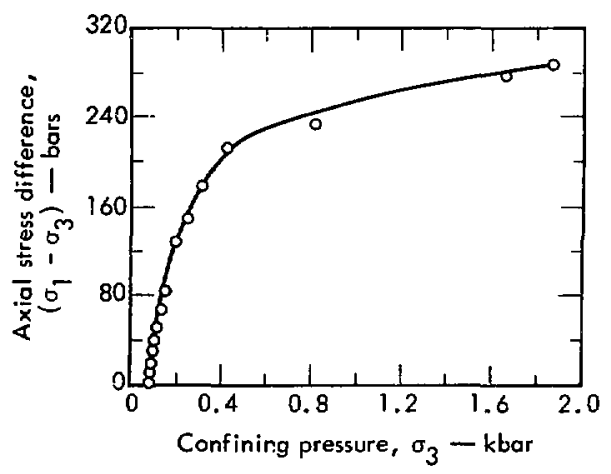

Fig. 8. Loading path in stress space under conditions of uniaxial strain from 80 bars for aggregated Merlin alluvium $(119 \mathrm{~m})$. 


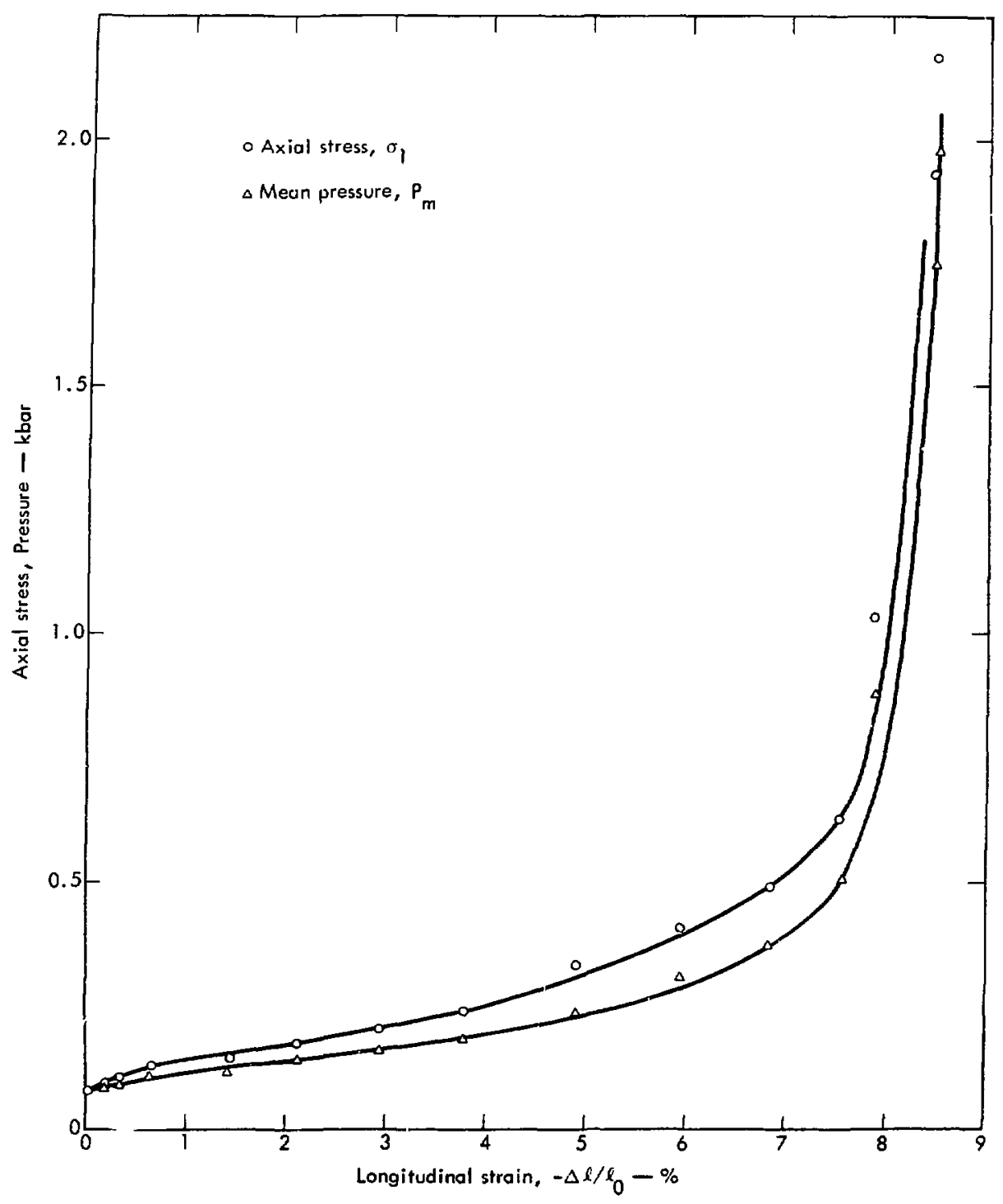

Fig. 9. Axial stress and mean pressure as functions of strain in uniaxial strain loading of aggregated Merlin ?luvium $(119 \mathrm{~m})$. 
intergranular friction apparently responsible for much of the stiffiness of the material. With increasing shear stress, individual grains will tend to move into existing pore space facilitated by the reduction of intergranular normal stresses or the breakdown of weak cement holding these grains together. As this takes place an enhanced compaction or softening of the volume strain-pressure relationship results. A similar, although not as pronounced, softening is observed in the hydrostatic pressure-v slume data previously presented and $i$ is envisioned that the presence of ma -oscopic shear stresses enhances softer ing by facilitating grain movement. Once most of the porosity is removed the loading curve shows pronounced stiffening. The slope $\sigma_{1} / \epsilon_{\ell}$ in $F i g .9$ is related to the compressional vaizcity, if elasticity is ássumed, and may be used to give some idea of the initial shock velocity in dynamic loading. With $d \epsilon_{r}=0, V_{P}^{2} \rho_{0}$ $=d \sigma_{1} / d \epsilon_{\ell}$ which yields a $v_{P}=0.73 \mathrm{~km}$ $\mathrm{sec}^{-1}$ from the initial slope. This value is slightly lower than the general value for this depth of about $1.1 \mathrm{~km} \mathrm{sec}^{-1}$ measured in an uphole survey ${ }^{8}$ in Yucca Flat and suggests that, even at the lowest stress level ( $\sigma_{1}-\sigma_{3}=5$ bars), inelastic deformation may have already had a pronounced effect. Similar low values were obtained in shock loading at stress levels of several hundred bars by Petersen etal. on a reconstituted alluvium from Frenchman's Flat.

The aample of alluvium partially disaggregated $(212 \mathrm{~m}$, density and water content not available) was loaded in uniaxial strain after loading hydrostatically to 60 bars. A stress difference/radial

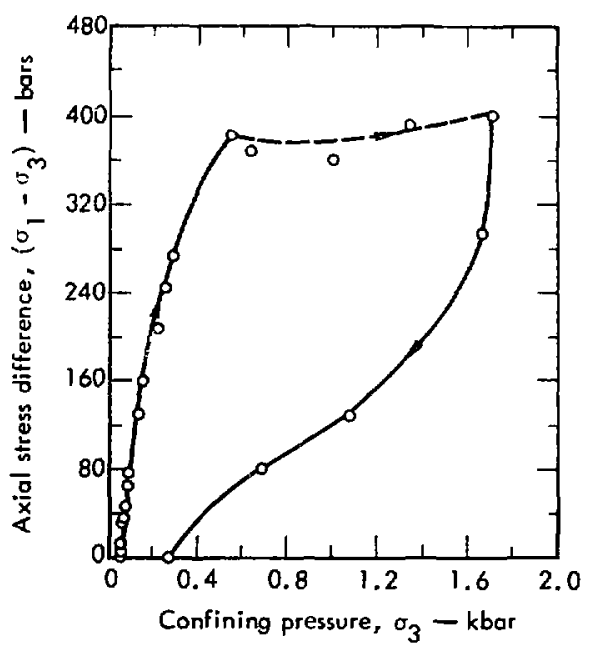

Fig. 10. Uniaxial strain loading is i unloading path for partially recon:tituted Merlin alluvium $(212 \mathrm{~m})$.

stress path (Fig. 10) very similar to the aggregated material is observed. The shear stresses attained are slightly higher but the curve nevertheless shows a similar increasing inelasticity. The corresponding strain data (Fig. 11) are also similar, showing a softening before pronounced stiffening and an increasing stress difference. The initial loading slope (neglecting slope to zero point) yields a $V_{P}=0.6 \mathrm{~km} \mathrm{sec}^{-1}$, slightly lower than for the aggregated sample. In addition this sample was unloaded in uniaxial strain after attainment of maximum pressure. It is seen that unloading from the stiff portion of the loading curve results in permaneint compaction and that in general the unloading data fall on an extrapolation of the stiff loading curve.

The data in Figs. 8-11 may be used to compute effective moduli characteristic 


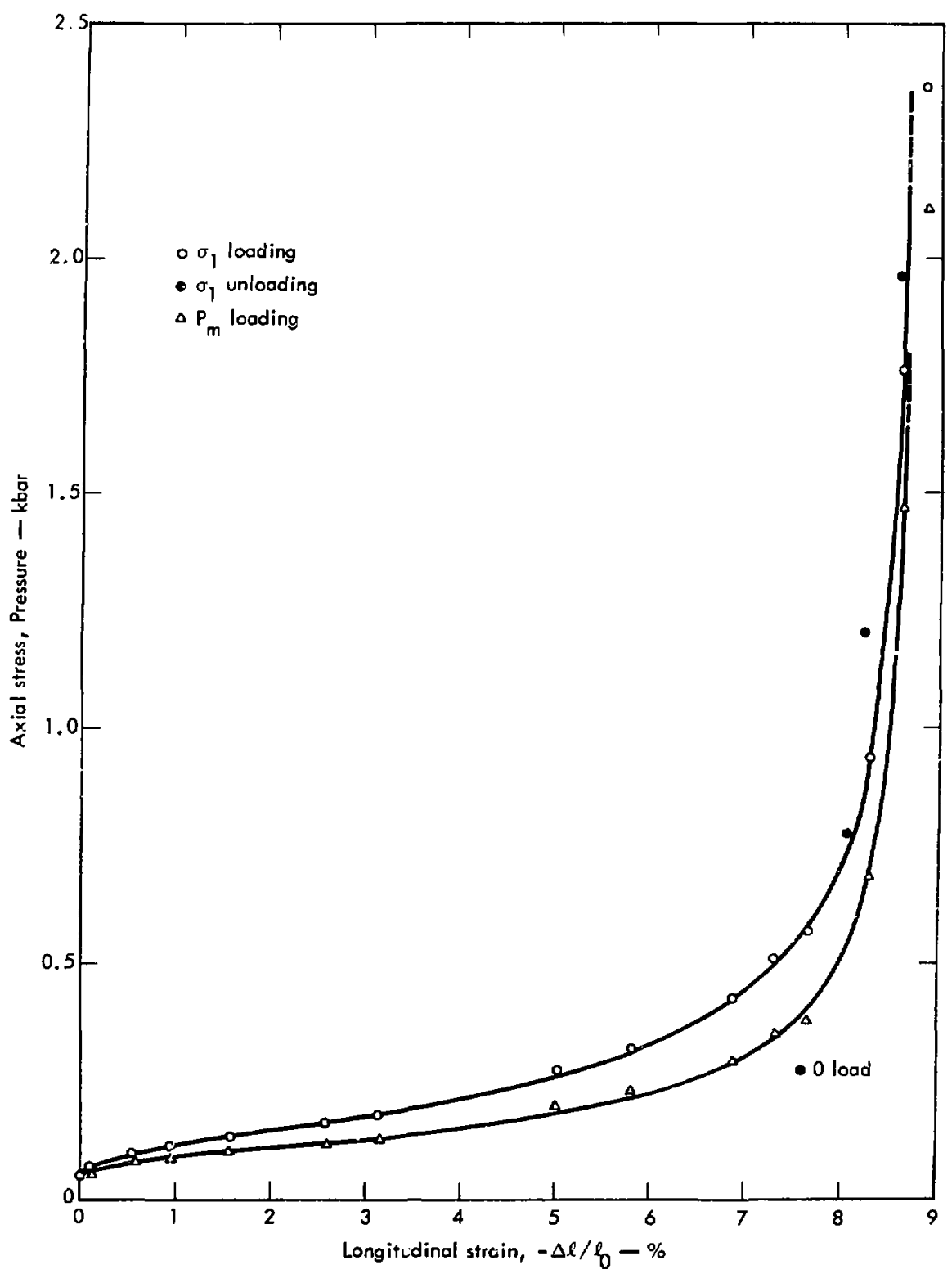

Fig. 11. Stress-strain relations in uniaxial strain for partially reconstituted Merlin alluvium $(212 \mathrm{~m})$. 
of loading and unloajing. The initial loading slope in Figs, 8 and 9 is of a material with an effective bulk modulus $K=49 \mathrm{kbar}$ and an effective shear modulus $\mu=2.7 \mathrm{kbar}$, which for the elastic solution corresponds to a Poisson's ratio of 0.21. Both the shear modulus and the bulk modulus initially decrease with increasing load, the shear modulus showing a more rapid percentage decrease and consequently resulting in an increase in the effective Poisson's ratio. Typical values for the softened region in Fig. 9 are $K=2.4 \mathrm{kbar}, \mu=0.9 \mathrm{kbar}, \nu=0.34$ at $\sigma_{1}=236$ bars, $\sigma_{3}=152$ bars. In the final stiff portion at $\sigma_{1}=1047$ bars, $\sigma_{3}=810$ bars, $K=112$ kbar, $\mu=3.6 \mathrm{kbar}$ and $\nu=0.49$, values typical of failed material with little cohesion. Data could not be obtained on unloading because of loss of strain gages at peak of loading. The reconstituted sample values are similar enough at comparable levels to suggest that the values given above are meaningful, if two runs can be considered

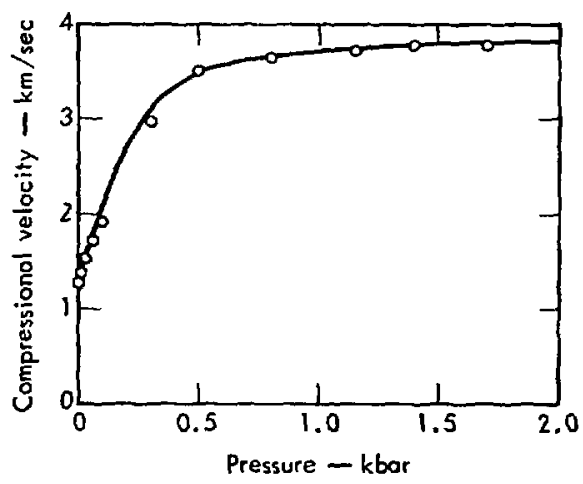

Fig. 12. Ultrasonic compressional velocity as a function of hydrostatic pressure for reconstituted alluvium. so. In addition to the data being internally consistent, they agree with both the hydrostatic pressure-volume data and the strength data. In Fig. 9 for instance, the offset between axial stress and mean pressure at 2 kbar $\mathrm{P}_{\mathrm{m}}$ indicates a shear strength of 135 bars, in excellent agreement with the measured shear strength at this mean pressure. On unloading the reconstituted material continues to behave as a failed material and usloads with an effective Poisson's ratio of 0.47 . The unloading $K$ is $-140 \mathrm{kbar}$ and $\mu \sim 100 \mathrm{kbar}$.

\section{ULTRASONIC COMPRESSIONAL VELOCITY}

Compressional velocity for a sample fabricated from 50\% "NTS fines" and $50 \%$ "NTS pea gravel" was determined by the pulse transmission technique outlined in the Appendix. This alluvium was obtained from P.rea 1, NTS; approximate coordinates are $\mathrm{N} 84,000, E 64,000$. The sample cylinder, $10 \mathrm{~cm}$ diam by $17 \mathrm{~cm}$, was prepared by adding $10 \%$ water by weight and then handpacking the material to a density of $\sim 1.55 \mathrm{~g} / \mathrm{cc}$. Urethane jackets isulate the sample from the pressure fluid, and transmit pressure.

Phase velocity as a function of pressure is plotted in Fig. 12. Change in path length with pressure was estimated from strain measurements made during hydrostatic compression of similar alluvium. The first phase arrival for sample cylinders of this geometry is the compressional body wave. ${ }^{10}$ Since the principal resonance of the transducers is - $150 \mathrm{kHz}$, the wavelengths of strain waves in the sainple range from $9 \mathrm{~mm}$ at ambient pressure to $25 \mathrm{~mm}$ at $2 \mathrm{kbar}$. These 
wavilengths are long compared to the dominant particle size in the alluvium, minimizing scattering predicted by classical theory. A rapid increase of compressional velocity occurs with pressure as the effective deformation moduli increase. The decrease of porosity and improved grain-to-grain contact increase the moduli, overwhelming the increase in bulk density. Such behavior is generally inaracteristic of porous earih materials, but the increase in velocity, $\sim 200 \%$ at 2 kbar, is unusually large. For example, the analogous velocity increase for $50 \%$ water saturated Rio Blanco sandstone is $\sim 50 \%,{ }^{11}$ for a $20 \%$ saturated Diamond Dust tuff $\sim 20 \%$. The velocities to pressures of 55 bars are in good agreement with velocities for Ue3-ct reported by Carison and Hearst ${ }^{8}$ over appropriate depth intervals, assuming stresses in the borehole wall are purely hydrostatic.

\section{Acknowledgments}

The authurs gratefully ackmowledge the assis:ance of E. Joslyn, V. LaGuardia, E. Lilley and H. D. Stromberg in carrying out this work. B. Kelly constructed much of the s.pparatus and aided in sample preparátion. D. R. Stephens was in- strumental in conceiving this project, in designing the equipment, and in gathering preliminary pressure-volume data. We thank J. R. Hearst for supplying the alluvium core sample and associated data. 


\section{References}

1. I.. D. Ramspott, R. L. Braun, and W. F. Wadleigh, Mineral Composition, U Content, and Grain Density of Drill Hole Samples from Yucca Flat, Nevada Test Site, Lawrence Livermore Laboratory, Rept. UCRL-50915 (1970).

2. D. R. Stephens and E. M. Lilley, "Loading-Unloading Pressure Volume Curves for Rock" in Proc. ANS Topical Meeting, Engineering with Nuclear Explosives, Las Vegas, Jev., 1970 (American Nuclear Society, 1970) p. 89.

3. J. Handin and R. V. Hager, Jr., Amer. Ass. Petrol. Geol. Bull. 41, 1 (1957).

4. R. N. Schock, H. C. Heard, and D. R. Stephens, High-Pressure Mechanical Properties of Rocks from Wagon Wheel No. 1, Pinedale Wyoming, Lawrence Livermore Laboratory, UCRL-50963, (1970).

5. H. C. Heard and H. Washington, Lawrence Livermore Laboratory, Internal Document 1MD Technical Note 18, (1970). Readers outside the Laboratory who desire further information on LLL internal documents should address their inquiries to the Technical Information Department, Lawrence Livermore Laboratory, Livermore, California 94550.

6. D. R. Stephers, H. C. Heard, and R. N. Schock, High Pressure Mechanical Properties of Tuff irom the Diamond Dust Site, Lawrence Livermore Laboratory, Rept. UCRL-50858 (1970).

7. H. C. Heard, R. N. Schock, and D. R. Stephens, High Pressure Mechanical Properties of Tuff from the Diamond Mine Site, Lawrence Livermore Laboratory, Rept. UCRL-51039 (1971).

8. R. C. Carlson and J. R. Hearst, Physical Properties of (mostly northern) Yucca Flat Alluvium and Tuff, Lawrence Livermore Laboratory, Rept. IICID-15848 (1971).

9. C. F. Petersen, W. J. Murri, and M. Cowperthwaite, J. Geophysical Res. 75, $2063(1970)$.

10. W. M. Ewing, W. S. Tardetsky, and F. Press, Elastic Waves in Layered Media Chap. 1 (McGraw-Hill Book Co., Inc., New York, N. Y., 1959).

11. R. N. Scliock, H. C. Heard, and D. R. Stephens, High Pressure Mechanical Properties of Rocks from the Rio Blanco Gas Stimulation Experiment, Lawrence Livermore Laboratory, Rept. UCRL-51260 (1972). 


\section{Appendix A}

\section{SAM PLES}

Since the alluvium cores were extremely heterogeneous and only weakly cc solidated, new techniques were developud to investigate their raechanicai properties. Large cylindrical samples were removed intact from the coring tube, whenever possible. In some irstances rusting of the core tube mad : intact recovery impossible. Typical samples are illustrated in Fig. A-i. Sample cores were then immediately jacketed in, $16 \mathrm{~cm}$ lead, which isolated them from the pres sure medium during pressure-volume and uniaxial stress and uniaxial strain tests. Urethane jackets were used during ultrasonic velocity measurements since ultrasonic waves propagating in a lead jacket would have obscured waves passing through the highly attenuating alluvium.

\section{APPARATUS}

Large sampic deformation experiments were performed in a hydrostatic pistoncylinder device, with a working volume $30 \mathrm{~cm}$ long and $20 \mathrm{~cm} \mathrm{i.d.} \mathrm{The} \mathrm{apparatus}$ is illustrated schematically in Fig. A-2. Hydrostatic pressures up to 2 kbar can be applied independently of encl load. The bottom end of the pressure chamber is closed by a movable piston, which is fluid driven to supply axial stresses up to $\sim 13 \mathrm{kbar}$ on a $10 \mathrm{~cm}$ diam sample at 2 kbar confining pressure. Twentyfour electrical leads enter the pressure vessel by feed-throughs in the high pressure plug which seals the top end of the vessel.
Confining pressure is measured with a Bourdon tube gage accurate to $0.1 \%$. End load is determined by an internally mountad load cell, accurate to $: \%$, calibrated by a dead-weight gage. Calculated stresses are corrected for the strength of the lead jacket. Foil gages bonded to the specimen jacket around a circumfererce near the middle of the cylindric i sample (Fig. A-1) provide three dimensional strain measurement. Twelve gages, of which half measure circumferential strain and half measur c longitudinal strains, are wired so as to average strains on opposite sides of the sample. This reduces the effects of local inhomogeneities.

Since the response of foil gages to large inelastic strains is not well known, alternate strain measurements are made during pressure-volume and uniaxial stress tests. Comparisons with pistondisplacement compressibility measurements indicated a systematic error in gage readings, possibly due to strain hardening of the gages. Results reported here have been corrected for $30 \%$ low reading of volume strains. Sample voiumes after the tests are also determined by fluid displacement. Axial deformations are measured directly with the linear potentiometer during uniaxial stress experiments.

Ultrasonic compressional velocity is measured by adapting the well known pulse transmission technique for measuremerits in low $-Q$, heterogeneous alluvial material (see Fig. A-3). A $2 \mathrm{kV}$ rectangular voltage pulse is applied to the piezaelectric element at the top of the 


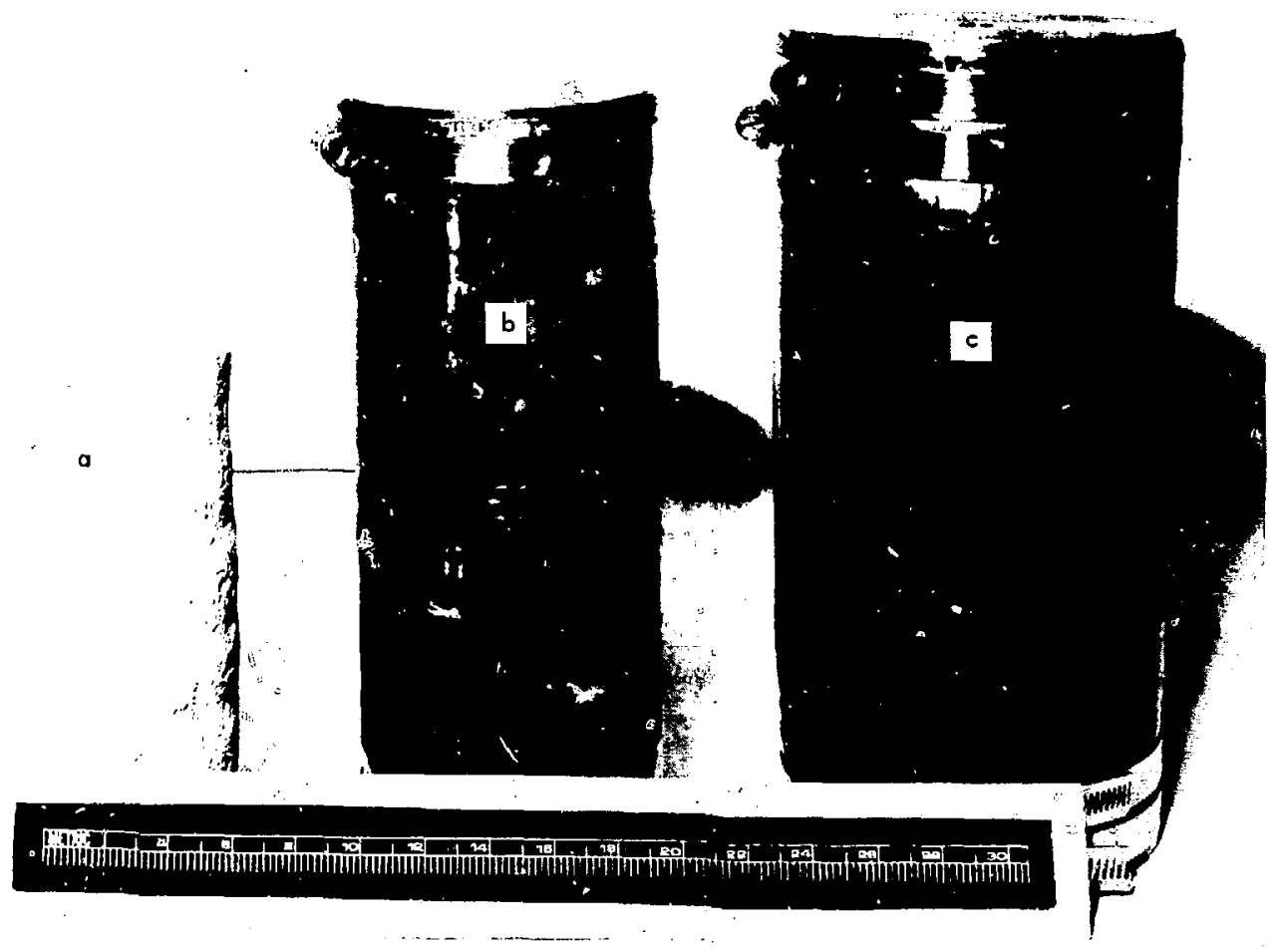

Fig. A-1. Representative large samples:

a. Alluvium core after hydrostatic compression to 2 kbar.

b. Ten $\mathrm{cm}$ diam sample after hydrostatic compression. Note placement of strain gauges. c. Jacketed $15 \mathrm{~cm}$ diam sample. 


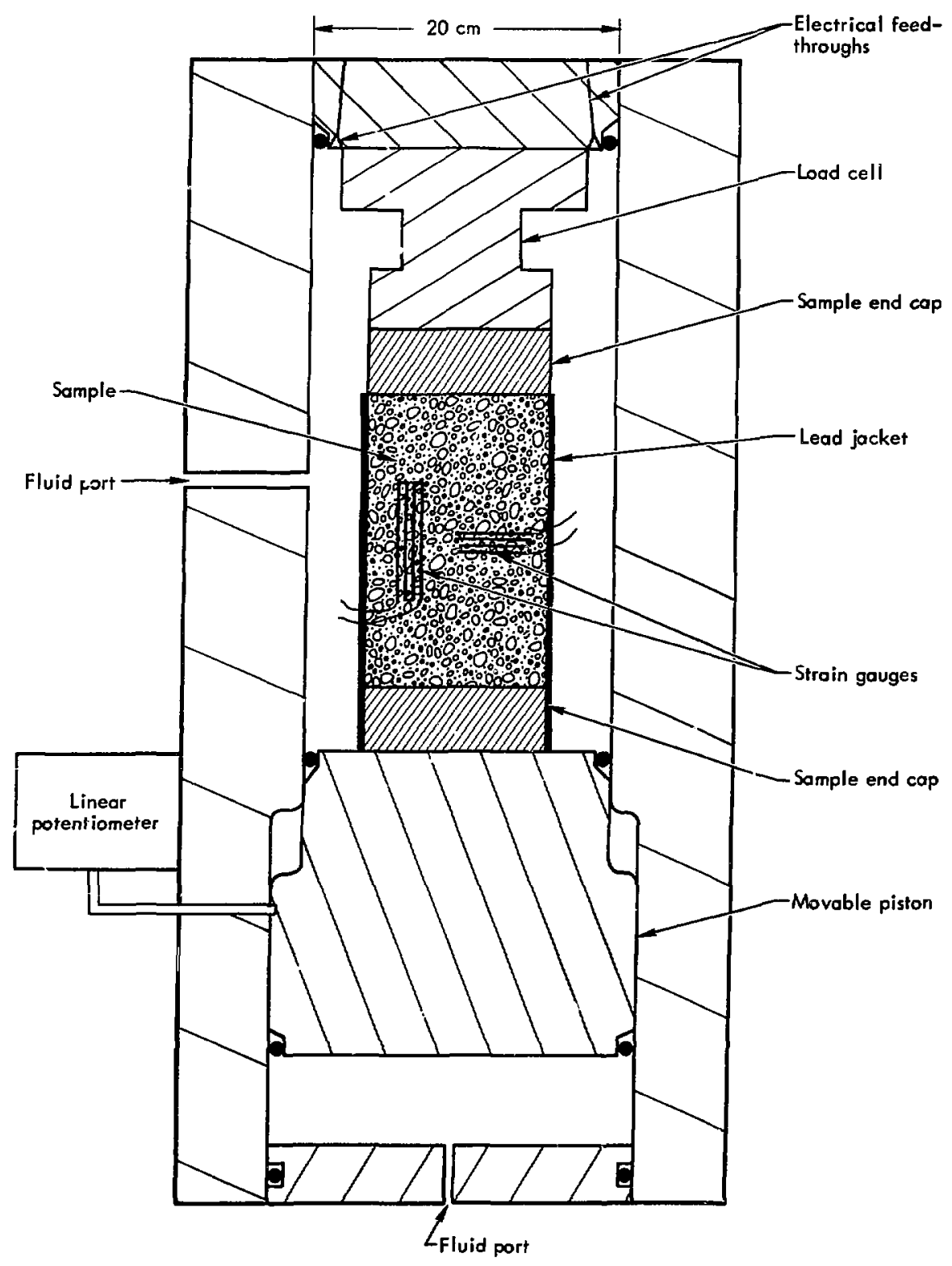

Fig. A-2. Schematic diagram of apparatus. 


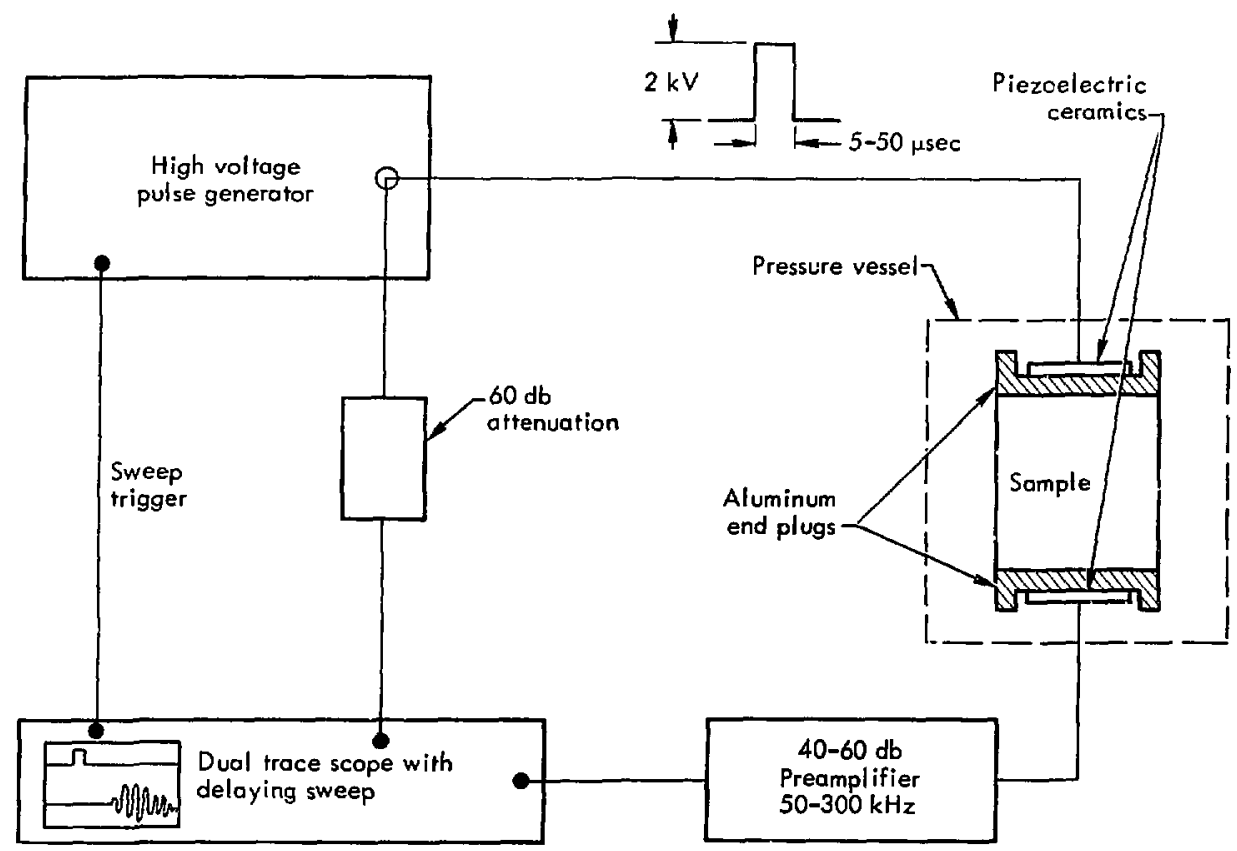

Fig. A-3. Pulse transmission system for ultrasonic velocity measurements.

sample and the small amplitude strain wave generated is detected by a similar element at the other end. The active elements are poly $:$ ystalline ceramic $\mathrm{Pb}\left(\mathrm{Zr}, \mathrm{Ti} \mathrm{O}_{3}\right.$ discs, $1.27 \mathrm{~cm}$ thick by $5.08 \mathrm{~cm}$ diam. bonded with polysty rene resin to aluminum end plugs, which act as buffer rods. The principal resonance of the discs is $\sim 150 \mathrm{kHz}$.

Velocity is calculated from travel times measured with the delaying sweep of a dual-trace oscilloscope, accurate to 1\%. Travel times are corrected for system delays by timing the delay in the aluminum end plugs with no sample present. Additional delays introduced by the buffer rod-sample bonds are undetectable and are neglected. The change in speci- men length with pressure is estimated from measured pressure-volume curves for samples of similar material, although longitudinal strain can he measured directly with slight modification of the ultrasonic system if more accurate determinations of the path length are required. Transducer rise time, signal attenuation and uncertainty in sample length limit accuracy to $\pm 5 \%$ for results reported here. Velocities reported for confining pressures greater than 50 bars are more reliabJe because signal attenuation drops dramatically. Although these measurements were made in a hydrostatic stress field, the apparatus can be used to measure ultrasonic velocity as the sample is subjected to additional deviatoric stresses. 
A PDP-9 computer is used extensively in data acquisition and plotting. The machine is now used in a closedloop control system which monitors stresses and strains, and constrains the stress-strain relation to specified conditions. Possible loading-unloading paths include combinations of hydrostatic compression, uniaxial stress, and uniaxial strain. 


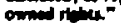

Printed in USA. Available from the National Technical Information Center, National Bureau of Standards,

U. S. Department of Commerce, Springfield, Virginia 22151 Price: Printed Copy \$3.00; Microfiche $\$ 0.65$. 